\title{
SIMULATION OF AUTOMATIC CONTROL OF AN IRRIGATION CANAL
}

\author{
D. Lozano ${ }^{\mathrm{a}}$, C. Arranja ${ }^{\mathrm{b}}, \mathrm{M} . \mathrm{Rijo}^{\mathrm{b}}, \mathrm{L}$. Mateos $^{\mathrm{a}^{*}}$ \\ ${ }^{a}$ Instituto de Agricultura Sostenible, CSIC, Córdoba, Spain \\ ${ }^{b}$ Departamento de Engenharia Rural, Universidade de Évora, Portugal
}

\section{Abstract}

Improved water management and efficient investment in the modernization of irrigation schemes are essential measures in many countries to satisfy the increasing demand for water. Automatic control of the main canals is one method for increasing the efficiency and flexibility of irrigation systems. In 2005, one canal in the irrigation scheme 'Sector BXII del Bajo Guadalquivir' was monitored. This canal is representative of irrigation schemes in Southern Spain; it is divided into four pools and supplies an area of 5,154 ha. Ultrasonic sensors and pressure transducers were used to record the opening of gates and water levels at the upstream and downstream ends of each canal pool. Using the recorded data and the SIC (Simulation of Irrigation Canals) hydraulic model, two canal control options (local upstream control and distant downstream control) were evaluated using a Proportional-Integral control algorithm. First, the SIC model was calibrated and validated under steady-state conditions. Then the proportional and integral gains of the PI algorithm were calibrated. The controllers were tested using theoretical demand changes (constant outflow followed by a sudden demand increase or decrease) and real demand changes generated on the basis of a spatially distributed crop water balance that included a number of sources of variability (random and not random) in the determination of field irrigation timing and depth. The results obtained show that only the distant downstream controller was able, quickly and automatically, to adjust the canal dynamics to the varying water demands; it achieved this efficiently and with few spills at the canal tail, even when there were sudden and significant flow variations.

Keywords: flexibility of water delivery, on-demand operation, local upstream control, distant downstream control, proportional-integral controller 